before us? This is as scientific an experiment as can be made, and the same applies to most of the other facts. Whilst writing this an old woman, aged 72 years, has applied for advice with cancer of the breast. She has bacon for breakfast and bacon for dinner. She lives in an ancient toll. bar house on an unfrequented road, she seldom goes out, and she can get no other food. Has not this woman, in a certain sense, made herself the subject of a scientific experiment? If this theory should turn out to be true its use would be chiefly in prevention, for it is not likely that deprivation of salt would cure an already established disease, although it might check its advance. It may, however, be tried, and also tried along with any other mode of treatment, as with a view to prevent recurrence after surgical operations, or with oöphorectomy and thyroid in cancer of the breast, as has been so ably advocated by Dr. G. T. Beatson and Mr. G. E. Herman, to whom, and especially to Mr. Roger Williams and Mr. Haviland, I tender my thanks for the many interesting papers from which I have taken most of my facts. Leeds.

\section{A CASE OF ASTHENIC BULBAR PARALYSIS (MYASTHENIA GRAVIS).}

By WALTER K. HUNTER, M.D., D.Sc. GlasG. ASSISTANT PHYSICIAN TO THE GLASGOW ROYAL INFIRMARY AND EXTRA PHYSICIAN TO THE HOYAL HOSPITAL FOR SICK CHILDREN, GLASGOW.

THE classification of the various forms of bulbar paralysis has always been a subject of much interest to the neurologist, but with the exception of the so-called "asthenic" variety their pathology seems now to be fairly well understood and to be no longer a matter of serious debate. With "asthenic" bulbar paralysis, however, it is different, for here no lesion has yet been found; and, indeed, it is a question if this disease should still be classified as a bulbar paralysis, and should not rather be considered as a general myasthenia in which the muscles supplied from the bulb are more specially affected than those receiving their enervation from other parts of the nervous system. But it is, perhaps, premature to discuss the pathogenesis of asthenic bulbar paralysis, for we have so few data to go upon. The disease, however, is very rare, not more than some 12 cases having been recorded in this country; and though there seems to have been a larger number than this abroad, I feel that I need have no hesitation in reporting a case which recently came under observation in the Glasgow Royal Infirmary, especially as I have made a somewhat careful microscopical examination of such parts of the nervous system as I have been able to obtain possession of.

A man, aged 58 years, was admitted to the Glasgow Royal Infirmary under the care of Dr. J. L. Steven on Nov. 17th, 1899, with a complaint of difficulty in speaking and swallowing and of an intermittent weakness in the extensor muscles of the neck. These symptoms had set in some two or three months before admission, and the patient thought that they were partly the result of his having carried on his head, on two successive days, a heavy load of books, for on the second day he was quite exhausted and felt very "nervous." Since this time his head had tended to droop forwards on to the chest. This was specially marked if he had been walking for a while, for then the head would fall forwards, usually towards the left, necessitating his lifting it up again with his hands. This symptom gradually got worse and sometimes the head could not be kept upright unless held up in that position. 'The defect in speech would only come on after he had been talking for some time, and after a rest the speaking was always more fluent and distinct. The difficulty in swallowing was also intermittent, and when present consisted in what the patient called a "spluttering and coughing" over his food. At such times the liquids would come back through the nose. Three weeks before admission there was some slight weakness noticed in both arms, especially the left, and occasionally there was a flexor contraction in the second, third, and fourth fingers of the right hand. The patient had been a snldier for 21 years and a good deal of this time was spent in India. He had had several attacks of ague and with one of these he was in hospital for 10 months. He had scarlet fever and measles in childhood, but could not remember having had rheumatism. He had suffered from hæmorrhoids almost all his life and from time to time lost a considerable amount of blood. He had been a total abstainer since 1877. The family history was of no importance; it showed no evidenceof nervous ailment among any of his relatives.

On admission the patient was noted to be pale and anæmic and he had quite the appearance of one suffering from a more or less profound anæmia. There was no evidence of paralysis in any of the muscles of the face. The tongue could be protruded without much ditticulty, but on examining the fauces it was noted that there was a firm adhesion between the left tonsil and the postero-lateral part of the dorsum of the tongue (this, the patient said, had dated from the attack of scarlet fever when he was six years old, but all the time he was in the army and performing the duties of a non-commissiod officer it in no way affected his power of speech.) The speech varied greatly in distinctness from time to time Sometimes it was. very suggestive of the articulation of bulbar paralysis; at other times there was just a slight nasal quality in the words. As the patient talked his articulation got worse but after a period of rest it was. greatly improved. During the first few days in the hospital he at times complained that he could not swallow his tood, and if he tried to do so there was usually a good deal of coughing and the fluids would return through the nose. But this was by no means constant, and frequently he would swallow both solids and liquids with no apparent difficulty. The most striking physical sign, however, was what at first looked like a spasmodic contraction of the flexors of the neck, causing the head to fall forwards and towards one or other side on to the chest. The patient would prevent this by supporting the forehead with his fingers; or, again, he would clasp his hands behind his neck, this seeming as if it supported some weakness in the extensors of the neck, for he complained of a sense of weakness in that region. When he began to walk he would hold himselfi fairly erect, but after a few steps the head would fall forwards on to the chest, and it was quite evident that when walking there was even a greater difficulty in holding the head erect than when he was sitting still. Careful examination of the neck at these times could elicit no appearance of spasm in the sterno-mastoids or in any other muscles of the neck, and it was quite evident that the fault lay in the trapezius and possibly in the erector spinæ muscles. There seemed, too, to be a certain amount of wasting in the upper fibres of the trapezius. There was complaint of a sense of weakness in the left hand. but no definite paralysis could be made out. The left hand registered 19 kilogrammes and the right 30 kilogrammes. At times there was a distinct. spasmodic flexion at the metacarpo-phalangeal joints of the second, third, and fourth fingers of the right hand, and when this was so it was with difficulty that the spasm could be overcome by passive movement. There was no loss of power in the legs and the patient seemed to walk without any apparent trouble. The patellar reflexes were unduly active, but there was neither knee clonusnor ankle clonus. There was no defect of sensation in the arms or legs. Examination of the eyes showed the visual acuity to be fairly normal and there was no contraction of the fields of vision. The pupils. were equal and responded readily to light, but rather sluggishly to accommodation. There was some slight paralysis of the right internal rectus, for when the patient looked towards the left the right eyeball lagged behind the left, and there was crossed diplopia beginning at the mid line and increasing as the image passed to the left. Examination of the heart, lungs, and kidneys proved these organs to be healthy.

From the time of admission onwards the progress of the case was slow, but always for the worse. From Dec. 20th the head was almost constantly lying down on the chest and the weakness in the hands and arms was so marked that the patient had difficulty in giving the head the support necessary to raine it up. At this date the right hand registered 20" kilogrammes and the left 14 kilogrammes. Articulation, it is noted, varied, but at times it was so bad that it was impossible to understand what the patient was talking about. The difficulty in swallowing had now become an urgent symptom and some days later it was necessary to give food by means of a stomach tube. On Jan. 8th, 1900, an attack of urgent dyspnoea lasting 10 minutes set in. The distress. was extreme, though the patient complained of no actual pain. He was quile conscious throughout and there was no cyanosis. On the 21st and 22nd there were again similar 
signs of dyspncea, but not so severe though of longer duration. The last attack was of five hours' duration and ended with the death of the patient. For a few days preceding this there were noted to be ptosis of the left eye and an occasional strabismus in the right eye.

At the post-mortem examination the body was seen to be much emaciated, and there was general atrophy of the internal organs. The heart was small but was otherwise healthy. The liver was also small and greatly atrophied in its left lobe, which had a cicatrix in its anterior surface extending deep into one of the portal areas. This might have been the result of a syphilitic gumma, but the healing was so complete that one could not be certain. The kidneys and spleen were small but quite healthy. The stomach and intestines were atrophied and the intestines showed a considerable general catarrhal condition of their mucous membrane. The brain and cord presented to the naked eye perfectly healthy appearances.

The pons, medulla, and cord were fixed in formol (10 per cent.), and later parts were transferrerl to Müller's fluid. Sections were stained by $(a)$ Weigert's method, $(b)$ Nissl's method, and (c) with hæmatoxylin and eosin. With Weigert's staining sections from different levels of the pons, medulla, and cord were carefully examined, but these all seemed to be perfectly normal. There was no suggestion of any degenerative change in any of the motor or sensory tracts or in any of the anterior or posterior merve roots. With Nissl's stain the results were practically the same. Special attention was paid to the third and fourth segments of the cord (which contain ganglion cells of the spinal accessory and phrenic nerves), but no abnormality was to be found. Throughout the whole cord the motor ganglion sells stained extremely well and only a very small proportion of "ghost-cells" was to be found. On counting the cells in the various groups of the anterior horns there was doubtless a diminution of about 30 per cent. in their number. This, however, did not affect one group more than another and seemed to be the same for all levels of the cord. In my experience it is usual to have in old people such a diminution in the number of ganglion cells, and therefore I think that for the case under consideration it has no special significance. Many cells contained yellow pigment granules. This was most marked in the lumbo-sacral region, where quite 50 per cent. of the ganglion cells were pigmented and where many had their Nissl granules almost entirely replaced by the pigment. The pigment was faintly yellow and was made up of very fine granules (the granules were finer and the yellow colour was fainter than is usually found in ganglion cells). This pigmentation was less marked in the cells of the dorsal and cervical regions. In the pons and medulla the appearances corresponded to those in the cord. The ganglion cells of the twelfth, tenth (motor), seventh, and fifth (motor) nuclei seemed to be perfectly normal. Of these the cells of the seventh were the only ones that contained any considerable amount of pigment. The section stained with Nissl's method did not include the third, fourth, and sixth nuclei. The cells of the motor cortex showed no definite abnormality. In the sections stained with hamatoxylin and eosin there was little that was abnormal to note. The vessels seemed unduly dilated (this may have been due to the fixing in formol), and many showed a distinct colloid degeneration in their walls. In some sections, too, there seemed to be a slight dilatation of the perivascular spaces, but there was no apparent exudation from the vessels, and there were no hæmorrhages.

It will be observed that none of the peripheral nerves were examined. This was unfortunate, for though the inter. mittent nature of the symptoms did not point to a neuritis yet the case is incomplete without a histological examination of the nerves. The affected muscles, too, should have been examined, especially in regard to the nerve-endings. The case clinically, however, presents a typical example of the so-called asthenic bulbar paralysis, or, perhaps more correctly, myasthenia gravis. This, I think, will be evident to anyone who is familiar with that condition; and for those who are not the admirable " digest" by Dr. Harry Campbell and Dr. Edwin Bramwell in the Summer Number, 1900, of Brain, will give an ample account of this interesting disease.

In conclusion, I have to thank Dr. Steven for his kindness in placing at my disposal the clinical notes of this case and for permission to publish it I am likewise indebted to Dr. C. Workman who also placed at my disposal for microscopical examination the brain and spinal corrl.

Glasgow.

\section{DURATION OF RESIDENCE IN SANA- TORIUMS FOR PULMONARY TUBERCULOSIS.}

BY THOMPSON CAMPBELL, M.D. GLASG., LATIE PHYSTCIAN TO THE CONSUMPTION SANATORIUM, BRIDGE OF WEIR, N.B.

WHILE the question of the erection of sanatoriums is being discussed in various parts of the country a point which calls for some consideration is the length of time during which patients suffering from pulmonary tuberculosis will require to be kept under treatment to give some reasonable prospect of restoration to health.

Naturally, the earlier the stage of the disease at the time of admission the shorter will be the period of residence necessary. Among the working classes, unfortunately, the seeming necessity for pursuing their employment as long as possible militates against their receiving institutional treatment before the disease has made considerable inroads, and until they recognise the fact that it will be greatly to their advantage to cease from work immediately the nature of the disease is made known to them by their medical attendants directors of sanatoriums must be prepared to prolong the period of residence considerably beyond the usual hospital term. Another fact which calls for as extended a period of treatment as the circumstances of the sanatorium permit is that a number of the patients will return to home surroundings which are not ideal in their conditions, though if properly trained and impressed with the necessity of continuing to follow out the important details of the regimen they will improve these conditions as far as lies in their power. To fix a limit of six weeks is to confess that the aim of an institution is merely the amelioration of the patient's condition, and would result in filling the "State on dismissal" column of a sanatorium report with the word "Improved"-not a very valuable or substantial benefit in the case of a disease which we propose to combat on the assumption that it is, within certain limits, a curable malady.

The shortest period of treatment-that is, in a case in which the physical signs give evidence that the disease is in an early stage-will by most sanatorium physicians be fixed at three months. Thus a patient may present such signs as diminution of percussion resonance at one apex, prolongation of expiration, increased vocal resonance, and a few small clicking râles accompanying the breath sounds; and with a small quantity of expectoration, a moderate pulse-rate, and no great evening exacerbation of temperature, a good result may be secured after three months' sanatorium treatment. Unfortunately, however, only a small percentage of patients belonging to the working classes seek treatment at a time when such a period would suffice, and the majority admitted are found to have one lung affected in an intermediate, and the other in an early, stage. The physical signs, therefore, may be found to comprise dulness to percussion over the upper lobe of one lung, bronchial breathing, marked increase of vocal resonance, and a series of mediumsized clicking râles accompanying inspiration and expiration, with diminution of percussion resonance over the other apex, prolonged expiration, and a few small clicking râles. In such cases a period of treatment less than six months will not be found to give an approach to recovery, and this should therefore be the average limit, taking into consideration on the one hand the maximum benefit to the individual and on the other the pressure on the accommodation which exists in most charitable institutions. Thus, each bed could on an average accommodate only two patients in a year, and in making provision for consumptives this factor should be kept in view by public bodies and the directors of sanatoriums for the poorer classes if their aim be to restore sufferers to the position of wage-earners. It need hardly be said that a longer residence would be beneficial in a number of cases, but until the meagre provision which exists at present is largely extended a period of six months may be looked upon as a fair limit.

The question may, however, arise whether it is advisable to retain patients who are not found after a certain interval to be making satisfactory progress towards recovery ; but if care has been taken to debar from admission cases which 